\title{
Role of Price on Replanting Decisions of Rubber: An Application of Almon Lag Model
}

\author{
J. Edirisinghe and D. Perera *
}

\begin{abstract}
Rubber is one of the major plantation crops cultivated in Sri Lanka. It gives an environmental service apart from its economic potential. To have a continuous supply of rubber, it is vital that the balance between mature and immature rubber stands be maintained in the long run. In order to do this, at least $3 \%$ of the total area under rubber needs to be re-planted annually. However, in the recent past, replanting as well as new planting has declined. One of the major variables that affect the replanting decision by farmers is the price of rubber. Hence, this study evaluated the role played by the lagged price of rubber in replanting decision making. Almon lag model was employed to data related to rubber prices from 1980 to 2004. A second degree polynomial was found to be best in describing the data, as expected. The maximum time lag was found to be eight years but a lag of four years had the highest impact on the replanting decision. The paper discusses the policy implications of the delayed response of replanting to prices.
\end{abstract}

\section{Introduction}

Rubber is one of the three main plantation crops in Sri Lanka and it is grown mainly in the Wet Zone of the country. At present, it occupies 114,000 ha of land and the sector contributes $0.7 \%$ of the Gross Domestic Product (Central Bank of Sri Lanka, 2004). Rubber is said to be one of the highest value added commodities. It is used in diverse industries from tyres to pharmaceuticals. In the year 2004, export earnings from value added rubber products stood at Rs. 28,935.40 million, whereas exports of raw rubber could yield only Rs. 5,137 million as export earnings. In addition to its economic potential, it has an edge over other perennial crops because of its environmental services, which is believed to be only second to natural forests. Rubber has a 30 year economic lifespan and is usually replanted after 30 years. Thus, the ideal situation in rubber cultivation in the country is to have $80 \%$ of the land in the mature (yielding) phase and $20 \%$ in the immature

The authors are, respectively, Lecturer and Assistant Lecturer Faculty of Agriculture and Plantation Management, Wayamba University of Sri Lanka. 
phase (Handbook of Rubber Agronomy, 2002). The Rubber Research Institute of Sri Lanka (RRISL) advocates replanting 3\% of the extent annually to maintain this balance. However, due to low prices that prevailed during 19952002 period (Figure 1) and thus low income generated from rubber cultivation in the recent past, rubber industry was termed as a 'sunset industry'.

Figure 1: $\quad$ Real prices of natural rubber in Sri Lanka (1990-2004)

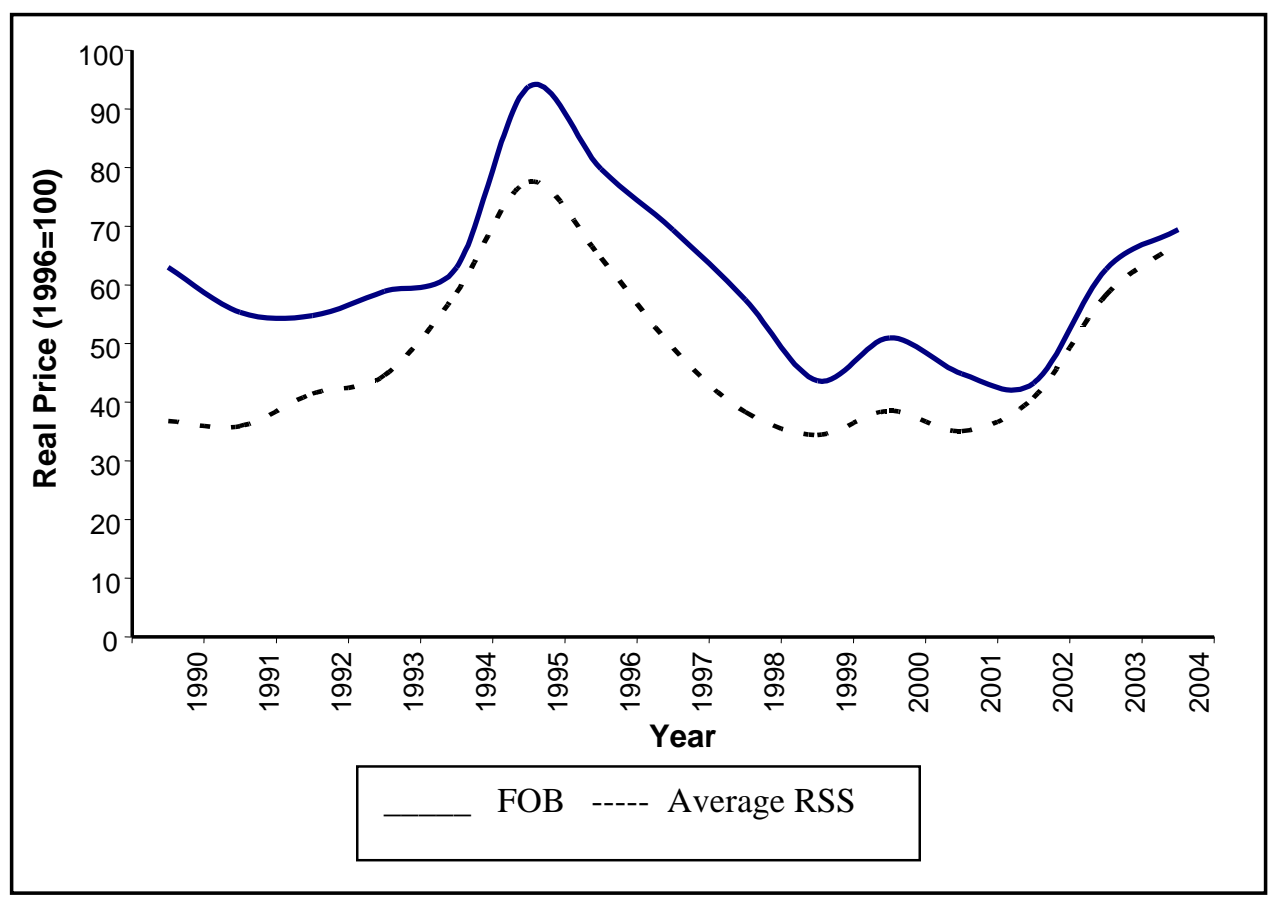

Source: Plantation Sector Statistical Hand Book, Ministry of Plantation Institute of Sri Lanka, 2005.

Especially after the Asian financial crisis, and probably assisted by the elimination of International Natural Rubber Agreement (INRA), rubber prices went down sharply, and have only been able to pick up from late 2002 (Figure 2). Hence, delays in replanting and abandoning of new plantings were observed in all rubber growing districts. 
Figure 2: $\quad$ Replanting and new planting of rubber in Sri Lanka (19902004)

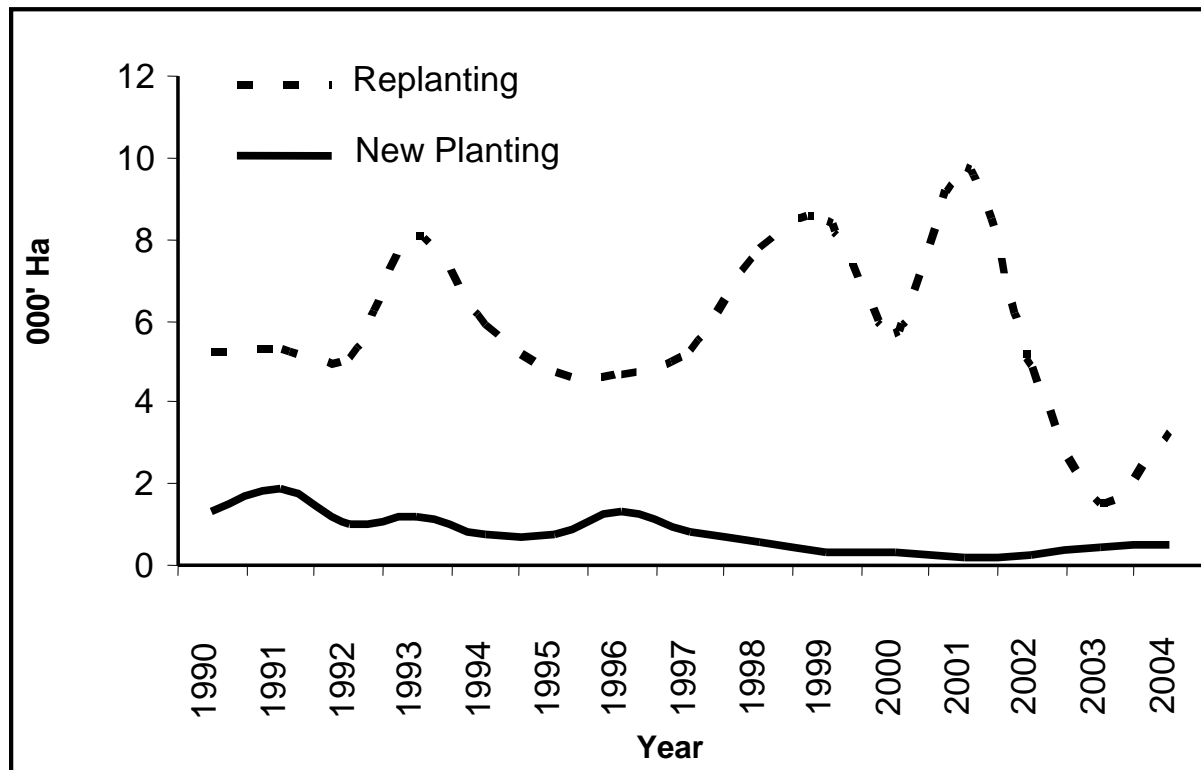

Source: Plantation Sector Statistical Hand Book, Ministry of Plantation Institute of Sri Lanka, 2005.

The replanted area, which was 5,434 ha in 1980, declined to 1,510 ha in 2003. Hence, the rubber extents have declined rapidly in the country and the present figure of 116,000 ha is only a little over one half of 205,601 ha cultivated in 1981. The decline in extent had an adverse impact on production of raw rubber as expected and it has declined from 133.2 Mn. kg in 1980 to a mere $95 \mathrm{Mn} . \mathrm{kg}$ in 2004 (Ministry of Plantation Industries of Sri Lanka, 2005). Therefore, with this continuous decline in production, apart from the export demand, meeting the ever rising domestic consumption will be a challenge in the years to come (Figure 3 ). 
Figure 3: $\quad$ Domestic consumption of rubber in Sri Lanka (1990-2004)

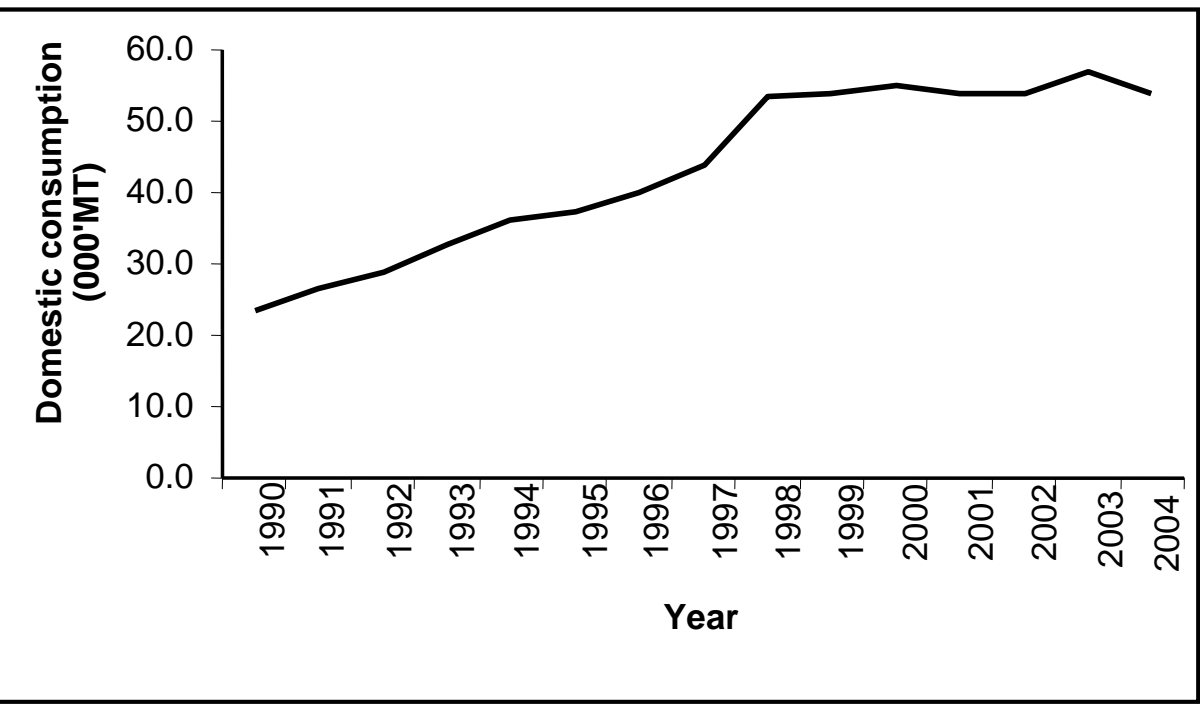

Source: Plantation Sector Statistical Hand Book, Ministry of Plantation Institute of Sri Lanka, 2005.

Replanting rubber after the economical lifespan of 30 years is vital in order to have a maximum long term supply of rubber to meet the country's growing demand. However, the evidence is that during low price periods replanting is also at a minimum and some move out from rubber cultivation. Hence, the linkages between replanting and prices are of policy significance. The questions that are of interest are; do the past prices affect replanting decisions of rubber growers? If so what is the pattern of the effect? If prices go up this year, will farmers replant their existing 30 year old plantations this year? Or do they wait few more years? Therefore, this study was carried out to study how prices influence the replanting decision of rubber in the country. This included replanting by smallholders, state estates and plantation management companies.

\section{The Conceptual Framework}


A prudent planter tries to maximize his returns from the plot of land he owns. Output prices play a key role in the planter's income/return. By replanting a plot of rubber land, the owner is foregoing income from that plot of land at least for five years, since the immature period of rubber spans for 56 years. Thus she/he would not replant her/his rubber land if the hike in prices is considered temporary. If so the farmer would keep her/his old rubber land intact to obtain maximum benefits from the short term price increment (even a 30 year old rubber tree will give latex though it's not economical). However, she/he would go for replanting if she/he is certain that the price hike is long term. This implies that replanting decision is influenced by the expected price. Therefore, there is a lag in response of prices on replanting. Hence, the following relationship is developed between replanting (and also new planting) extent and prices.

$$
Y_{t}=\alpha+\sum_{i=0}^{T} \beta_{i} X_{t-i}+U_{t}
$$

where,

$Y_{t}=$ Replanted+New planted extent at time $t(000$ ' ha /year)

$X_{t-i}=$ Lagged average price of Ribbed Smoked Sheets (RSS) at Colombo auction deflated by GDP deflator

$\alpha$ and $\beta$ are coefficients, $U_{t}=$ Random error term

Here, replanting (and new planting) is assumed to be affected by past prices. Among different distributed lag models in literature, Koyk and Almon lag scheme are two models in economics that can be used to estimate lagged behavior in economic variables. It is expected that the impact of prices on replanting may increase from current year and will reach a maximum and decline again. That is, the most recent prices as well as most distant prices both will not have any real positive impact on replanting. However, the Koyck model assumes that the $\beta$ values decay exponentially; therefore, it essentially states that as the lag increases the relative importance of prices decline. This is not the expected case with rubber replanting. In contrast, the Almon model assumes that the $\beta$ values can vary in a polynomial manner. Thus, in the Almon lag, the restriction on declining importance of past prices is not there. Hence, in this study the Almon Polynomial Lag Model (APL) was used (Gujarati, 2004). This can be represented as, 


$$
Y_{t}=\alpha+\sum_{i=0}^{k} \beta_{i} X_{t-i}+U_{t}
$$

where, the $\beta$ vales are expected to behave in a polynomial manner.

Thus, generally $\beta$ values can be specified as,

$$
\beta_{i}=a_{0}+a_{1} i+a_{2} i^{2}+\ldots \ldots \ldots . .+a_{m} i^{m}
$$

By substituting (2) in (1);

$$
Y_{t}=\alpha+\sum_{i=0}^{k}\left(a_{0}+a_{1} i+a_{2} i^{2}+\ldots . .+a_{m} i^{m}\right) X_{t-i}+U_{t}
$$

This can be re-written as;

$$
Y_{t}=\alpha+a_{0} \sum_{i=0}^{k} X_{t-i}+a_{1} \sum_{i=0}^{k} i X_{t-i}+a_{2} \sum_{i=0}^{k} i^{2} X_{t-i}+\ldots \ldots \ldots+a_{m} \sum_{i=0}^{k} i^{m} X+U_{t}
$$

In the above equation, instead of $\sum X_{t-i}$, new variables are introduced as below,

$$
\begin{aligned}
& Z_{0 t}=\sum_{i=0}^{k} X_{t-i} ; \quad Z_{1 t}=\sum_{i=0}^{k} i X_{t-i} ; \\
& Z_{2 t}=\sum_{i=0}^{k} i^{2} X_{t-i} ; \ldots \ldots \ldots \ldots Z_{m t}=\sum_{i=0}^{k} i^{m} X_{t-i}
\end{aligned}
$$

Thus, the final estimating equation will be;

$$
Y_{t}=\alpha+a_{0} Z_{0 t}+a_{1} Z_{1 t}+a_{2} Z_{2 t}+\ldots \ldots \ldots .+a_{2} Z_{m t} U_{t}
$$

\section{Data and Analysis}

The Ministry of Plantation Industries publishes plantation sector statistics on an annual basis in the plantation sector statistical pocket book. 
This is a comprehensive data set on the rubber sector in the country. Annual replanting extents and prices from the year 1980 to 2004 were used in this analysis. The data reported are from smallholders, the state estates (Janatha Estate Development Board-JEDB and Sri Lanka State Plantation CorporationSLSPC) and the plantation management companies. The Almon lag model was estimated using the Ordinary Least Squares (OLS) technique.

\section{Results and Discussion}

In developing the above Almon lag model, two key decisions had to be made. First was the length of lag to be used while the second was the degree of polynomial. The length of lag was decided upon as in standard time series modeling by starting with a large lag period (10 in this case) and reducing the lag period sequentially checking to see whether the fit of the model deteriorates significantly (Gujarati, 2004). In obtaining the degree of polynomial the same logic was followed as well. In selecting the best model, low residual mean square, size of the ' $F$ ' value, adjusted $R^{2}$ and Akaike Information Criterion (AIC) was used. Though, most of these were used in model selection none of them was superior to the other (Gujarati, 2004). Hence, all these were used in selecting the best model.

Out of all the models tested, the model with a lag of 8 years had the lowest residual mean square, largest ' $F$ ' value and the highest adjusted $R$ '. However, AIC was lowest in the model with a lag of 6 years but the 'F' was not found to be significant in this model. Though, lag lengths 10 and 9 seemed better with AIC, lag 8 had the most number of individual parameters significant. Therefore, a lag of 8 years was used in constructing the polynomials (Table 1).

Table 1: $\quad$ OLS regression results for different lag lengths

\begin{tabular}{cclcc}
\hline Lag length & $\begin{array}{c}\text { Residual } \\
\text { Mean Square }\end{array}$ & F & Adjusted R $^{2}$ & ln AIC \\
\hline 10 & 1.825 & $3.61^{*}$ & 0.3953 & 1.019 \\
9 & 1.535 & $4.87^{*}$ & 0.4915 & 1.143 \\
8 & 1.534 & $4.87^{*}$ & 0.4916 & 1.143 \\
7 & 1.902 & $3.35^{*}$ & 0.3699 & 0.984 \\
6 & 2.413 & 2.00 & 0.2000 & 0.708 \\
\hline
\end{tabular}

* Significant at 5\% 
The next issue of obtaining the appropriate polynomial was also resolved in the same manner by running the regression repeatedly starting with a larger polynomial (Table 2).

Table 2: $\quad$ OLS regression results for different polynomials

\begin{tabular}{lcccc}
\hline \multicolumn{1}{c}{$\begin{array}{c}\text { Degree of } \\
\text { polynomial }\end{array}$} & $\begin{array}{c}\text { Residual } \\
\text { Mean } \\
\text { Square }\end{array}$ & F & Adjusted R & In AIC \\
\hline $5^{\text {th }}$ Degree & 1.534 & $4.87^{*}$ & 0.4916 & 1.143 \\
$4^{\text {th }}$ Degree & 1.674 & $4.85^{*}$ & 0.4453 & 0.965 \\
$3^{\text {rd }}$ Degree & 1.75 & $5.35^{*}$ & 0.4202 & 0.803 \\
$2^{\text {nd }}$ Degree & 1.699 & $7.2^{*}$ & 0.4368 & 0.704 \\
\hline *significant at 5\% & & & &
\end{tabular}

The $2^{\text {rd }}$ degree polynomial was selected as the best model for three reasons. It had the highest ' $F$ ' value, relatively lower residual mean square, lowest AIC and the significance of the variables in the model. Therefore, the second degree polynomial with a lag of 8 years was selected for final interpretation.

The results of the regression analysis on the estimating equation are as follows,

$$
\begin{gathered}
Y_{t}=\alpha+a_{0} Z_{0 t}+a_{1} Z_{1 t}+a_{2} Z_{2 t}+U_{t} \\
Y_{t}=8.59-3.48 Z_{0 t}+2.61 Z_{1 t}-0.33 Z_{2 t} \\
(1.208)(1.337) \quad(0.673) \quad(0.076) \\
\mathrm{R}^{2}=0.4368 \quad \mathrm{~F}=7.2 \text { d.f }=24
\end{gathered}
$$


Table 3: $\quad$ OLS estimates for $3^{\text {rd }}$ degree polynomial with lag of 8 years

\begin{tabular}{lccc}
\hline & Estimate & $\begin{array}{c}\text { Standard error of } \\
\text { the estimate }\end{array}$ & 't' ratio \\
\hline Constant & 8.59 & 1.208 & $7.11^{*}$ \\
$Z_{0 t}$ & -3.48 & 1.337 & $-2.60^{*}$ \\
$Z_{1 t}$ & 2.61 & 0.673 & $3.88^{*}$ \\
$Z_{2 t}$ & -0.33 & 0.076 & $-4.31^{*}$ \\
\hline
\end{tabular}

*Significant at $5 \%$

It follows from the above results (Table 3 ) that all the coefficients are highly significant at $P=0.05$. As the model included lagged values of the same independent variable, a high multicollinearity is expected. In order to verify this, multicollinearity diagnostic was also carried out. However, as Johnston (1984 cited in Gujarati, 2004) noted when $\mathrm{R}^{2}$ is high and regression coefficients are individually significant, multicollinearity may not pose a serious problem because individual coefficients happen to be numerically well in excess of the true values, so that the effect still shows up in spite of the inflated standard error (Johnston, 1984 cited in Gujarati, 2004). The problem of autocorrelation was accounted for by running the 'Prais Winsten' procedure in auto regression.

From the above estimations of $\alpha, a_{0}, a_{1}$ and $a_{2}$ it is possible to estimate the original $\beta$ values, which are the prime concern of the distributed lag model, based on equation (2). Hence, the estimated distributed lag model corresponding to equation (1) is as follows;

$$
\begin{aligned}
Y_{t}= & 8.59-3.48 X_{t}-1.2 X_{t-1}+0.45 X_{t-2}+1.38 X_{t-3}+1.68 X_{t-4}+1.32 X_{t-5}+ \\
& 0.3 X_{t-6}-1.38 X_{t-7}-3.72 X_{t-8}
\end{aligned}
$$

The above results indicate that the replanting decision at present is influenced by past prices in varying degrees. However, it should be noted that the negative and significant co-efficient in the current price is against theoretical expectations. It can be expected that the influence of current prices on replanting decisions would be low but it can never be negative. The highest impact on replanting was observed at a lag of four years which gives the highest coefficient implying that farmers' replanting decision is best influenced by medium term prices. It is also observed that the long term 
impacts of more than 6 years is also negative implying that farmers do not consider replanting based on too distant prices. Interestingly, this lag length of 6 years also corresponds with the average length of immature period for rubber. Their consideration of short term price hikes is not that favorable for replanting because of the fact that they try to use the price increment to its maximum by keeping all the mature extents intact so that the benefit of the increased price can be obtained from tapping all the area available to them, thus maximizing profit.

\section{Conclusions and Policy Implications}

It is evident from the foregoing analysis that farmers' replanting behavior is most affected by mid term lagged price level rather than the current prices. That is, there is a lagged response in replanting to prices. This was observed in 2002, where although the price increased considerably, any increase in replanting was not seen in the country other than in the government sponsored new planting in Moneragala. This delay can be due to many reasons. Firstly, a farmer who has a plot of rubber land that is in replanting stage will not tend to replant immediately when prices increase. $\mathrm{He} / \mathrm{she}$ would rather generate income from that land for a few years. Secondly, farmers may not be so positive about the price increment given the nature of heavy fluctuation in rubber prices. Thirdly, the delay can also be attributed to the fact that the time taken to execute the replanting operation may be higher in smallholder sector which is about $65 \%$ of the country's rubber extent. The delays may be in terms of issuing permits, subsidies, fertilizer etc. Therefore, speeding up the bureaucratic procedures in issuing permits and subsidies will speed up the replanting and thereby help to maintain the balance between mature and immature extents of rubber in the country. In addition, the delay in replanting by the estate sector also needs to be looked into and be addressed on an urgent basis. Otherwise a shortage of rubber is inevitable in future as mature extents have gone up considerably. Once they are replanted ultimately, there will be a limited extent of mature rubber to provide the country's growing demand.

\section{References}

Central Bank of Sri Lanka (2004). Annual Report. Central Bank of Sri Lanka, Colombo. 
Gujarati, D.N. (2004). Basic Econometrics. $4^{\text {th }}$ ed. McGraw-Hill Book Co.

Ministry of Plantation Industries of Sri Lanka. (2005). Plantation Sector Statistical Pocket Book. Ministry of Plantation Industries of Sri Lanka.

Rubber Research Institute of Sri Lanka (2002). Hand book on Rubber: Agronomy, RRISL, Agalawatta, Sri Lanka. 